\title{
Does Tracking and Feedback Boost Patrol Time in Hot Spots? Two Tests
}

\author{
Charlotte de Brito $^{1} \cdot$ Barak Ariel $^{2}$
}

Published online: 23 October 2017

C) The Author(s) 2017, corrected publication July/2018

\begin{abstract}
Research Question Do police officers complete more assigned patrols in targeted crime hot spots when their supervisors track and feedback data on the proportions of targeted patrols completed?

Data Uniformed police officers filled out 'patrol cards' indicating arrival and departure times at each scheduled hot spot patrol location within four large London railway stations, returning the cards to supervisors each shift. For the experiment, all patrol cards were forwarded to a central analysis unit, where they were digitised and turned into weekly reports for two of the four stations (test stations) but not the other two (control stations). The reports were expressed in a fraction composed of a denominator $=$ numbers of hot spot locations assigned for patrols (which varied widely from day to day), and a numerator $=$ number of locations at which patrols had been completed.

Methods Each week for 3 weeks, the central analysis unit sent reports on 'percent of assigned patrols completed' by day of the preceding week to the commanders of the two test stations and to higher-level commanders. The test station commanders were required to 'brief' their patrol teams on the proportion of patrols completed. Two sites assigned to control conditions received no such information but were still required to conduct hot spot patrols as their business as usual.

Findings One test station showed a $22 \%$ increase in assigned patrols completed, but the second test station showed no discernible effect of tracking and feedback compared to control conditions. These differences between test site results were associated with different leadership histories, turnover and communication styles in each site.

Conclusions Patrol dosage feedback was followed by increased patrol dosage delivered in relation to matched control sites, but only in one of two tests. These mixed findings suggest the potential value of further research on tracking and feedback, specifically
\end{abstract}

Barak Ariel

ba285@cam.ac.uk

1 British Transport Police, Cambridge, UK

2 University of Cambridge and Hebrew University, Cambridge, UK 
addressing the communication methods, rewards and penalties for line officers responding to the feedback.

Keywords Tracking $\cdot$ Hot spots $\cdot$ Patrol $\cdot$ Implementation

\section{Introduction: Tracking and Delivering Hot Spot Patrols}

Crime is highly concentrated in a small number of specific locations (Sherman et al. 1989 , 1995, 2007), usually in very small places, such as street addresses, city blocks and small pieces of land (Weisburd 2015). These micro-locations have been termed 'hot spots' (Sherman et al. 1989). There are profound practical meanings to these concentrations, particularly in terms of crime prevention. Increased uniformed officer presence in hot spots of crime and disorder has been suggested to have a modest yet significant effect in reducing crime (Sherman 2013; Braga et al. 2012). Moreover, visits of 15 min (Koper 1995) have been shown to have consistent deterrent effects across several studies (Koper 1995; Telep et al. 2012; Ariel et al. 2016; Ariel and Sherman 2012). Each of these claims has been widely studied in experiments with high internal and external validities.

What is less well known is how to ensure that uniformed police constables (PCs) and (in the UK) police community support officers (PCSOs) actually patrol with the patterns that have been tested. Rapid advancements in tracking technology allow many police forces to track their officers' whereabouts at all times (Wain and Ariel 2014). Yet knowing where police go is not enough. The question we address is how to deliver police presence in precise locations for precise periods of time. While there is good evidence that precision delivery is possible (Gibson et al. 2017), there is also good evidence that precision delivery is very difficult, with a high risk of failure (Goddard and Ariel 2014; Williams and Coupe 2017). The field needs more and better evidence on how to improve the delivery of police presence where and when it is needed most.

Evidence-based policing (EBP) is a process of using best evidence to make policing decisions for 'Targeting, Testing and Tracking' the use of resources, also known as the 'triple-T' model (Sherman 2013). When applied to hot spot policing, the model can incorporate evidence of where uniformed resources should be targeted to where they will have the most effect in deterring crime, in this case crime hot spots. This targeting is supported by evidence derived from testing through experimentation, which suggests that hot spot patrols reduce crime. But whether the patrols are delivered consistently based on the ways in which they were tested remains an open question, from 1 week to the next, to every patrol commander who directs officers to undertake targeted patrols. It is only by ongoing tracking of where the resources are deployed that the commanders can be sure that patrols will have the best effect promised by the tests. Even when commanders know that patrols are not being delivered, what has not been tested is how to shape the organisational behaviour of front-line police officers.

As Sherman et al. (2014b, p. 3) observed, 'criminologists are usually more interested in crime than in organizational behaviour'. When such a large number of police forces claim to be using hot spot policing as their method of patrol, we ignore questions of organisational behaviour at our peril. So when British Transport Police (BTP) decided to invest in a hot spot patrol strategy, it soon invested in research on how best to deliver 
patrol time in crime hot spots. This article reports the results of one such research project, which found that the same system worked very well under one leadership style, but not under another. These findings offer both practical and theoretical.

\section{Setting: The British Transport Police}

This article reports two separate tests conducted in 2016, within one police agency, of one way of using tracking data to increase hot spot patrol time. That police agency is the British Transport Police. The hot spots in question were all located within the premises of four major London railway stations, for which BTP has primary responsibility for territorial policing - using the same arrest powers and weaponry as the Metropolitan Police or any of the 43 territorial police agencies in England and Wales.

BTP is nonetheless a specialist police force, responsible for policing the railways throughout England, Wales and Scotland. About 8.6 million people use the rail network and its stations every day, and BTP is responsible for keeping the individuals in this transient environment safe and secure. BTP has just over 2000 uniformed PCs and around 350 PCSOs (see Ariel et al. 2016), with detective and management ranks, police staff and special constables making up the remainder of BTP's 5500 strong workforce. Since conducting a large randomised test of uniformed patrols in the London Underground with the Cambridge University in 2011, BTP has assigned a large proportion of its operational staff to carry out preventative visits in hot spots of crime all over BTP's nationwide jurisdiction.

The system for these patrol assignments is designed around evidence-based targeting. BTP analysts identify long-term hot spot locations, based on 3 years of crime data, to create 'patrol cards' to be used by BTP's patrolling workforce. Each patrolling $\mathrm{PC}$ or $\mathrm{PCSO}$, on a daily basis, is given a patrol card by their supervisor, showing them the hot spots they have a responsibility to visit, and the times during which they are due to make these patrols. This practice is clearly based on successful testing. Yet at the time our two tests were undertaken, there had been no system established for tracking whether the patrols were delivered as the patrol cards required. As of early 2016, no data had ever been made available to commanders on the number of hot spot visits carried out by this vast patrolling workforce. There was, in short, no dashboard for identifying areas or people in non-compliance, so that changes could be made where necessary to ensure individuals are at the right place, at the right time.

That fact, in itself, is hardly shocking. It was not very long ago that hospitals initiated tracking whether doctors washed their hands after touching infected patients. Yet the real importance of that analogy is that tracking by itself did not necessarily improve hand washing. Tracking data, in any human service, is merely a starting point. What it provides is a basis for discussing 'what's next?' If the tracking evaluations are good, then little needs to be done. But if they are not so good, then a wide range of options must be considered. Few hospitals, if any, have developed and tested an evidence-based system for improving hand-washing compliance. Few police agencies have developed and tested an evidence-based system for improving hot spot patrol compliance. Yet in both cases, tracking is the essential first step in the process of continuous improvement. 


\section{Research Question}

This research addresses that essential first step. It makes problematic what other studies assume: that police will patrol where and when they are directed to. It starts with the first step of tracking and proceeds to the most obvious second step: feeding back to the officers what the tracking data show. It is not obvious, however, that police (or doctors) will improve their compliance just because they are shown the tracking data. As an implicit act of criticism, feedback on failure to meet job expectations may be just as likely to promote defiance as compliance (Sherman 1993). The only way to know whether the assumption of compliance is valid or not is to test it. And no matter what the results of one test may be, more tests are needed to reveal any conditions under which the effects of an organisational policy might vary - succeeding, backfiring or having no effect.

A central feature of tracking is the technology used to track what people do and where they do it (see discussion below). The challenge BTP faces is the difficulty of adopting new technologies in a transport environment, where electronic signals face huge interference. Thus, the experiment reported here was not the one originally planned for this research, which would have used a more advanced technology.

BTP has spent several years in developing an automated officer tracking solution, yet there have been many obstacles to doing so. The most common commercial systems available rely on GPS signal, but there is no signal underground or in railway stations that are indoors, which form a large part of BTP's jurisdiction. Many options have been discussed and tested, with the preferred method being Wifi access point (AP) triangulation. Yet numerous obstacles have meant that deployment of smartphones required to geo-locate police officers and PCSOs has been repeatedly delayed.

As of August 2016, an automated system was almost — but not yet — available to test the effects of tracking and feedback on hot spot patrols. That interim tracking solution would have used Bluetooth Proximity Detectors (henceforth to be referred to as 'beacons') physically placed in hot spots of crime to locate patrol officers who are carrying a low-cost, low functionality smartphone with software which captures their proximity to a beacon. This study was expected to use the data collected from these beacons to provide an automated measure of patrol dosage. When that became impossible within the time frame available, a fallback plan was implemented. That plan, in fact, provides useful insights for police in many parts of the world where digital data collection of police locations is still many years away. Thus, the actual test, based on patrol locations self- reported by the police officers and PCSOs, may use methods that are less than ideal (see discussion in Wain and Ariel 2014), yet the findings are nevertheless informative for a basic understanding of police agency dynamics.

Thus, the question for this research article is not just the general question of whether tracking and feeding back patrol time in hot spots will increase time in those hot spots. It is, rather, the more useful and specific question of 'Whether two tests of providing tracking feedback on hot spot patrols, based on officer-reports of their locations, will consistently increase the amount of patrol dosage reported as delivered?'

Because the answer to this question was 'no', that required us to answer a further question: 'why was tracking and feeding back followed by increases in hot spot patrols completed in one test but not another?' While this second question is intrinsically more difficult to answer than the first, it is the key link between this initial study and further 
tests of ways to increase compliance with preventive patrol assignments in hot spots. Those questions are put into context by recent research literature on the issue.

\section{Using Tracking Outputs to Change Behaviour and Influence Outcomes}

In a recent paper, Sherman et al. (2014b) state that an essential requirement for success when implementing a hot spot patrol model within any force is that 'feeding back is essential to scaling up' (see also Ariel \& Partridge 2016). Sherman's Trinidad and Tobago Police Service team then created a Station Level Cop-Stat for Police Commanders, explaining how best to use tracking data to feedback with the aim of increasing police patrols and consequently reducing crime. Their use of transformational leadership may have been advantageous, using it is not fear of punishment but pride of achievement which will persuade officers to carry out the greatest volume of patrols possible. Their hypothesis was that using tracking feedback hand in hand with information on the positive crime reducing outcomes their patrol work is achieving would have the largest effect when inspiring individuals to patrol. They were not, however, able to test that hypothesis directly.

The nearest study to testing that hypothesis may be that by Ariel (2012), who tested the effects of feedback on the tax reporting behaviour of 4395 organisations in Israel through the dissemination of tax letters to two treatment groups. One group received a deterrence message, the other received a message of moral persuasion. Neither treatment condition was found to cause significantly greater compliance when compared to control conditions. But what may not work for retail businesses may still work for uniformed patrol officers.

\section{The Tracking of Hot Spot Patrol}

The most relevant literature may be the descriptions of how police patrols were tracked in the experiments previously discussed. What, if anything, was done to increase dosage in these particular experiments? What were the effects of these interventions - did they reduce crime as expected? The answers must be partly informed by the technologies of tracking they used.

Independent Field Observers The first randomised controlled trial of hot spot patrols was the Minneapolis Experiment (Sherman and Weisburd 1995). This study struggled with treatment fidelity after the initial 7 months of the experiment. But how did they even know? Before the age of GPS transponders in vehicles or radios, the Minneapolis experiment relied on manually generated data. Both self-reported patrol logs from police officers, as well as independent observations by a team of over 15 university researchers, measured the duration of police presence in each spot. Dosage was sustained for 7 months by providing patrol supervisors with weekly reports of the data submitted by officers from their patrol logs, as well as a monthly report of dosage as observed by the independent researchers. According to the patrol tracking data presented in the article, this encouragement was successful until a sharp rise in demand during summer months. But there was no test comparing the impact of giving feedback to not giving it. 
Supervisory Reports In British Transport Police's own hot spot patrol experiment, Operation Beck (Ariel and Sherman 2012), 57 of the London Underground's 115 highest crime platforms received 15 min patrols by uniformed police officers, four times a day during a late turn 3 p.m. -10 p.m. shift, 4 days a week (Wednesday to Saturday), for six consecutive months. Officers were manually tracked by having to call-in via Airwave radio to a team of dedicated Sergeants, who noted down 23,272 manually recorded arrival and departure times of the patrol teams to the platforms in question. The 24/7 effect of the platform visits was to reduce total crime counts by $14 \%$ on treated platforms relative to completely unpatrolled control stations and calls for service by $21 \%$. Unfortunately, there was no opportunity to test the impact of feedback of patrol time tracking to teams or individuals.

Call Centre Live Reporting of Patrol at Location Telep, Mitchell and their colleagues (2014) used a tracking system by which police officers reported to the dispatcher at the central call centre a special police activity code (D-HOT) by location whenever they began and ended their hot spot patrols in the Sacramento. Here again, any test of whether feedback of the tracking data was done or with what effect was beyond the scope of the study.

Automatic Vehicle Locator GPS Transponders At least three studies have used this technology for tracking hot spot patrols: Trinidad (Williams 2015), Weisburd et al. (2012, b) and Sacramento (Telep et al. 2014).

1) In 2013-2016, Trinidad and Tobago Police Service (TTPS) made great strides, perhaps more so than any other police organisation, in embedding an evidence-led, hot spot patrol approach using GPS transponders in patrol cars rather than manual methods to track patrol. A national roll out in Trinidad of tracking patrol minutes in hot spots increased patrols by $1000 \%$ and reduced homicide by 20\% (Kumar 2015, as cited by Sherman and Strang 2015). Yet there again, no test compared the provision of feedback to no provision of feedback about patrol times.

2) In Dallas, providing commanders with the hours of vehicle presence in a set of high crime treatment hot spots, as measured by an automated vehicle locator (AVL) system, resulted in achieving higher levels of patrol in hot spots and significant reductions in crime. However, the authors were unable to track whether the commanders fed that information down to the line supervisors and patrol officers (Weisburd et al. 2012a, p. 4). The authors conclude by stating that further research is required in other locations, focusing on hot spots, to better understand any possible value in using AVL for tracking and enhancing deployment.

3) In Sacramento, Mitchell (2016) added AVL data to the original CAD tracking to check for reliability of dosage differences between the experimental and control hot spots. She found the two data sources to yield consistent results, despite differences in the methods of drawing boundaries for the hot spots. Here again, however, the study was not designed to test the effect of feeding back the tracking data (or not) to those providing the patrols. 
GPS in Body-Worn Police Radios At least two hot spots studies used this technology to track patrol presence, both in the UK: Peterborough's Op Savvy (Ariel and Smallwood 2014) and the Birmingham Pop-up Patrol Experiment (Williams and Coupe 2017).

1) Op Savvy was a randomised controlled trial carried out in Peterborough, where all hot spots with 36 or more calls for service (CFS) were assigned to treatment or control. The intended treatment was three 15 min patrols in treatment hot spots, between 2 p.m. and 10 p.m., by PCSOs monitored by GPS captured by their radios, with business as usual activity carrying on in control hot spots (Ariel and Smallwood 2014). Yet the process of using the feedback data to increase compliance was not tested as part of the study.

2) In the Birmingham 'pop-up' patrol experiment comparing may short to fewer long patrols, Williams and Coupe (2017) also used GPS data from individual bodyworn radios to track compliance with a demanding patrol regime. On half of the 100 days of this experiment, foot patrol officers had to change hot spots every $5 \mathrm{~min}$. That technology was associated with a clear difference of dosage between two treatment groups, reflecting close tracking by the senior author as the sergeant in command of a neighbourhood team. But the study itself did not test different ways of dealing with the tracking data or make problematic the way in which the data were fed back to individuals.

In summary, there are diverse technologies being used to track how much time police spend in hot spots. From (1) direct observation to (2) radio reports to supervisors or (3) call centres to (4) vehicle locators and (5) body-worn radio transponders, many technologies are available. Yet there is virtually no evidence on what they do with that evidence in order to promote greater compliance in patrol dosage delivery-with or without success.

The present study's objective is to fill that that gap, with the most rudimentary comparative question: to feedback or not? It is unlikely that the effect of that decision can be understood from this study alone. Framing that question and conducting the two tests, however, can at least provide a prototype for larger studies and discussions of more evidence-based practices in putting evidence to work.

\section{Data}

In order to conduct two quasi-experimental tests, four sites featuring numerous hot spots were selected from within the BTP jurisdiction. The two tests were both designed at level 3 on the Maryland Scale (Sherman 1997): before-after comparisons in both a test site and a control site. Two of the four sites were assigned to treatment; two were assigned to control. The feedback treatment consisted of feeding back patrol dosage in specific hot spots to specific officers; the control treatment was to withhold the data needed for such feedback. All four sites were tasked to patrol their local hot spots well before the two tests began.

For a period of 1 week in all four sites, all officers were asked to continue to patrol the hot spots as normal, in order to establish a baseline. The only change in that period 
was an onset of data collection: the data on the patrol card returned to the central team was recorded and coded by study analysts. After the baseline week, the first week of the experiment (hereinafter known as 'week 1') commenced with the supervisors at two of the treatment locations receiving a feedback report from central BTP analysts. This report consisted of their PC and PCSO patrol data from the previous week. This procedure was carried out over the course of 3 weeks.

In the two feedback sites, the weekly hot spot patrol feedback report was given directly to the operational sergeants responsible for the daily deployment of PCs and PCSOs on patrol. The report was expressed in terms of number of visits to hot spots carried out by the PCs and PCSOs on duty and tasked to hot spot patrol. The test used a relatively 'soft' approach of disseminating the treatment report by email directly to the supervisors responsible for that location, asking for confirmation of receipt and allowing them to act on its contents in the manner they find most appropriate.

\section{Patrol Cards}

The data collected in this study to track patrol dosage is a sixth technology for hot spots (see above), one that is closest to the original Minneapolis experiment (Sherman and Weisburd 1995) which also had analysis staff compile and digitise police logs of arrival and departure times of every police car at specific hot spots. These logs were designed for the expressed purpose of feeding back tracking data to both the police chief and the four commanders. Yet in the case of BTP, the digitisation built on an existing system in place for some years.

At the time that our tests were conducted in 2016, BTP had been using hot spot patrol on its rail networks since the latter part of 2014 as the default patrol strategy for all uniformed staff. This meant that PCs or PCSOs are directed to patrol hot spots when not doing some other form of police work. They were assigned to carry out $15 \mathrm{~min}$ patrols in hot spots of crime as identified by BTP analysts. The technology of both assignment and tracking was called the 'patrol card', each of which describes where and when the hot spot patrols should take place.

A number of patrol cards are available for each shift for each station. These are assigned to individual officers by the supervisor on duty, as either solo or paired patrols. An example of a completed card is presented in Fig. 1.

While patrol cards pre-dated evidence-based targeting of hot spots, in 2016, BTP had no capacity to capture the data handwritten on the cards by the individuals on patrol. While they were submitted to the central project team responsible for the implementation of hot spot patrol within BTP, the cards were merely spot checked on an irregular basis. This experiment sought to digitise the data on these patrol cards for the first time, in a meaningful format which could be used to influence patrol dosage. An example of each of the two reports that were sent to the two experimental stations each week for 3 weeks is presented in Fig. 2.

The two level 3 experiments being described here were conducted as in-house projects, with all management, data logging and analysis carried out by BTP employees. Resources involved with the delivery of these tests consisted of the first author of this article, who was a police staff researcher at Inspector equivalent level, as well as the hot spot patrol Senior Responsible Owner (SRO) at chief superintendent level and a 


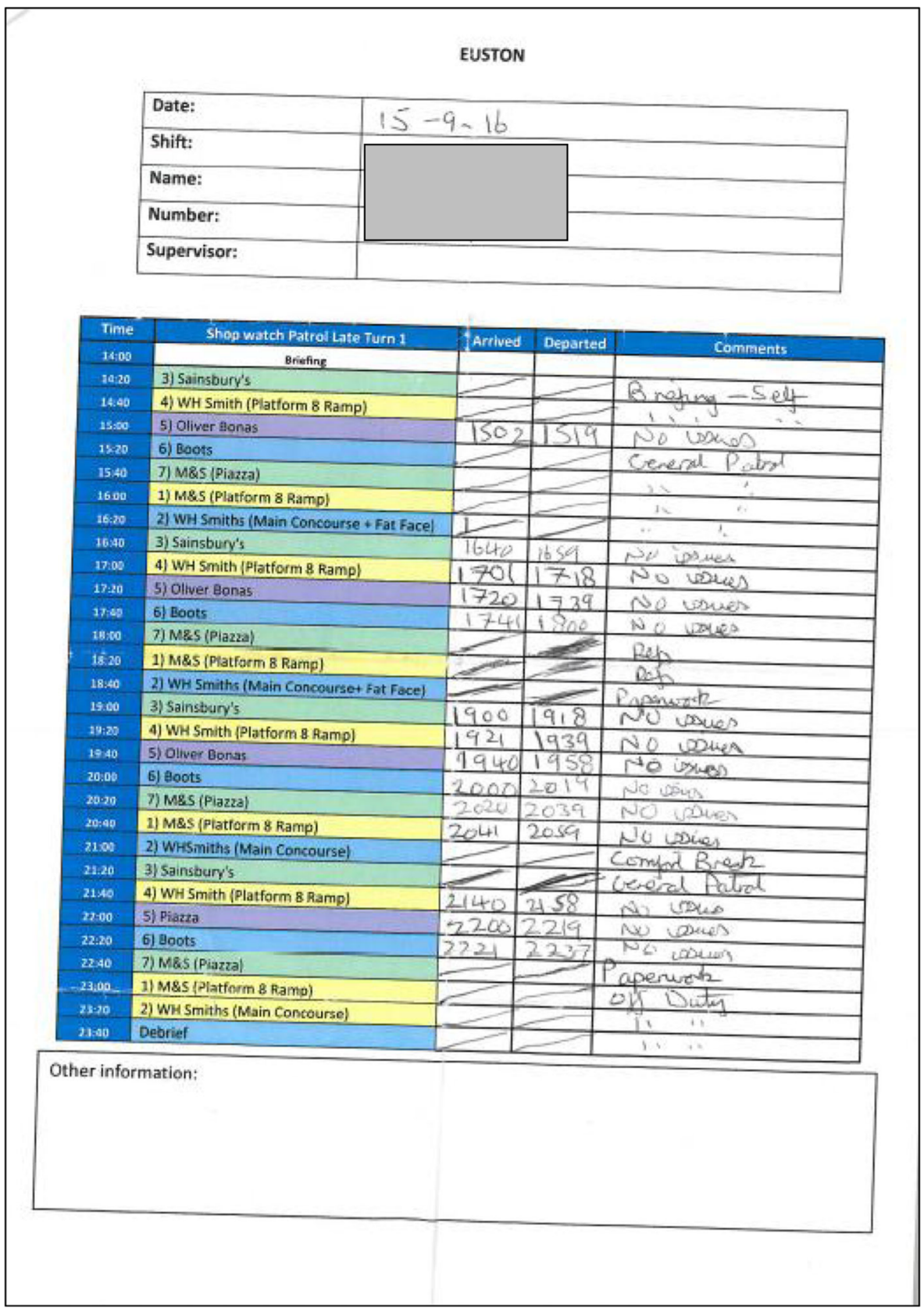

Fig. 1 Sample of patrol card (completed)

police staff patrol administrator. Additionally, the chief inspectors responsible for the sites to be part of the experiment were briefed and kept informed.

The specific experimental locations were four London 'hub' stations (large terminal overland stations with a permanent establishment of Inspectors, sergeants and 


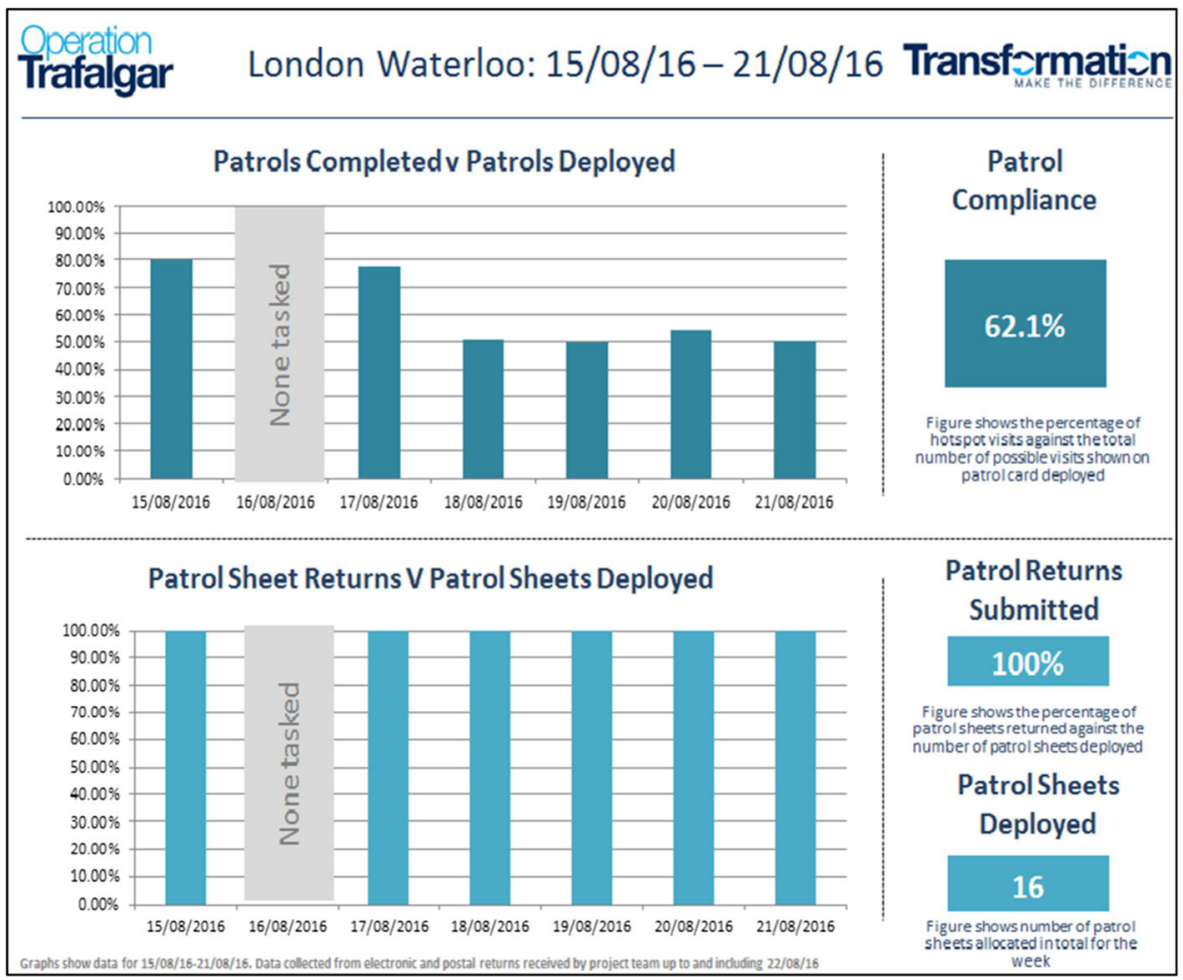

Fig. 2 Sample of patrol feedback report (London Waterloo)

patrolling PCs and PCSOs, dedicated to policing only that one station). The two treatment stations were London Euston and London Waterloo (including London Waterloo East). The two control stations were London Victoria and London Bridge. While seven locations in total were eligible for experimentation, the final four were selected through a quasi-random selection process.

The experiment was carried out as planned over 4 weeks in August, specifically between Monday 1 August 2016 and Sunday 28 August 2016. A timetable is shown as follows in Table 1 for clarity.

Table 1 Experimental timetable

\begin{tabular}{llll} 
Week & Date from and to & $\begin{array}{l}\text { Deadline for submitting } \\
\text { patrol card }\end{array}$ & $\begin{array}{l}\text { Date feedback report to be compiled and } \\
\text { disseminated }\end{array}$ \\
\hline Pretest & 01/August/16-07/August/16 & 08/August/16 & $08 /$ August $/ 16^{\mathrm{b}}$ \\
1 & 08/August/1-14/August/16 & $15 /$ August/16 & $15 /$ August $/ 16^{\mathrm{b}}$ \\
2 & 15/August/16-21/August/16 & 22/August/16 & $22 /$ August $/ 16^{\mathrm{b}}$ \\
3 & 22/August/16-28/August/16 & $29 /$ August/16 & $30 /$ August $/ 16^{\mathrm{b}, \mathrm{c}}$
\end{tabular}

\footnotetext{
${ }^{\mathrm{a}}$ Morning of

${ }^{\mathrm{b}}$ Afternoon of

${ }^{\mathrm{c}}$ Due to Bank Holiday on the 29/August/16
} 
Chief inspectors responsible for the four experimental sites were briefed by email 1 week in advance of the commencement of the experiment. The information provided was kept deliberately light, simply stating that the hot spot patrol central team were trialling a new feedback report based on the patrol card returns, and the chief inspectors were given a copy of the timetable for the 'trial'. They were not briefed on which sites were in the treatment group and which were in control; the word 'experiment' was deliberately not used.

Patrol supervisors in all four sites were told that they would need to submit to the central team the patrol cards tasked out and completed by their patrollers, on a daily or weekly basis, by email or by internal post. The two treatment sites were told they would receive a feedback report the week following submission of those weeks patrol cards.

Patrol cards were to be filled in manually during patrols by the individual PC and PCSO patrollers to show the visits they completed. The cards were then to be sent by the train station's BTP administrative staff into the central BTP analysis team (either by internal post, or scanned and sent via email). The central analysis team (off-site, under direction of the first author) then entered all patrol card data into an Excel spread sheet. A feedback report was compiled for the two treatment sites and disseminated to these two sites (but not controls). This feedback report showed (1) a summary of the data from the previous week, including the overall percentage of hot spot patrols 'achieved' against those 'required', (2) a summary by day of the week and (3) information on the percentage of returns received. These feedback reports were sent by email from the BTP patrol administrator to the supervisors at the two treatment sites, on a Monday afternoon. The chief superintendent SRO for hot spot patrol within BTP was copied into these emails.

\section{Variables and Measures}

The two tests of feedback sought to detect changes in the dependent variable of patrol dosage, measured in hot spot visits. The independent variable was whether or not the local commanders received the patrol feedback from the central analysis team.

The key units of analysis used to measure patrol dosage was a 'hot spot visit', defined as a uniformed PC or PCSO physically standing in a hot spot of crime. These visits were allotted in $20 \mathrm{~min}$ intervals on individually assigned patrol cards (15 min for the patrol itself, $5 \mathrm{~min}$ for travel to the next location); however, the capacity was not available for this experiment to log the actual number of minutes spent in a hot spot. The only unit of analysis was hot spot visits. Any visits where two individuals patrolled together on a double patrol were counted as one visit. This information was recorded by the officer at the time of patrol on a paper patrol card, which was then submitted to the supervisor at the end of their shift and subsequently submitted to the central team for logging.

A BTP hot spot of crime is identified by BTP analysts. They are micro-locations within transport stations, such as individual platforms or in-the-station shops with high levels of crime. The hot spots are identified by calculating the micro-locations which account for $50 \%$ of the crime in all of the micro-locations over a 3-year period. 
For this experiment, the hot spots were already defined by in house BTP Analysts and were not amended for the duration of the experiment.

A set of three outcome measures based on individual hot spots were captured for the 4 weeks during which the experiment was in operation. The first was the number of individual hot spot visits carried out by one individual on one shift (henceforth known as visits 'completed', with double patrol visits were counted as one visit). The second was the maximum number of possible hot spot visits which could be carried out on one patrol (hereinafter referred to as required number of visits). The third was the number of patrols cards tasked in each station on each day for each shift.

The research team decided that 'missing' patrol cards would not be 'chased'. These were cards assigned by the local supervisor to a PC or PCSO, but not submitted back to the central team and therefore whose data was not logged. The decision not to chase the cares was made to ensure that the experiment was conducted using operational business as usual conditions. Yet it is important to note that missing patrol cards were highlighted as missing in the weekly feedback report. The potential data on visits completed and visits required was not included in the analysis done for the feedback or for the present research. For example, if two patrol cards were assigned, each with 10 visits required, but only one card was returned to the central analysis team, and this one patrol card showed that 5 visits were completed, the percentage of compliance would be calculated as $5 / 10$ as opposed to $5 / 20$.

As additional outcome measures, the crime and calls for service volumes for each of the sites were gathered for each week during the experimental period.

Measuring the feedback treatment was accomplished by noting the time and date on which the feedback was sent by email. The central analysis team then noted that confirmation of receipt of feedback was received. The team also noted that the report had been briefed out, with the time and date also recorded.

\section{Methods}

\section{Experimental Feedback Treatment Conditions}

The experiment tested one treatment condition deployed in both treatment sites: the sending of a weekly feedback report via email directly to the operational supervisors responsible for the daily hot spot patrol deployment of PCs and PCSOs within that station. The chief superintendent acting as the SRO for hot spot patrol within BTP was copied into each email, and the supervisors asked to confirm within $24 \mathrm{~h}$ via a set template that the feedback had been received and briefed out to the PCs and PCSOs on patrol. It was not specified how the feedback was to be briefed out. This was left to the discretion of the supervisor (Table 2).

The feedback reports were sent via email to the sergeants at that station, copying in the relevant Inspector and also the chief superintendent with overall responsibility for hot spot patrol. The Sergeants were given $24 \mathrm{~h}$ in which to confirm that they had received the report and that it had been briefed out to their teams. This treatment was deployed in each of the two 'feedback' test sites, as intended, once for each of 4 weeks as shown in Table 1. 
Table 2 Information included in weekly feedback reports

Information

Total hot spot visits carried out for the week

Overall percentage for the entire week of completed hot spot patrols carried out against the total number

'required' as tasked on the patrol cards

Percentage of 'completed' hot spot patrols carried out against those 'required' for each day of the week

Overall percentage of patrol cards returned against patrol cards deployed

Percentage of patrol cards returned for each day of the week

Total number of patrol cards tasked that week

\section{Control Site Conditions}

The supervisors at each control site were asked to submit the same information as the treatment sites, except for anything to do with the feedback reports - which were not sent to the control sites. No further contact was made with these sites and no feedback or follow up on submitted returns took place.

\section{Findings}

\section{Experimental Delivery}

Was the experiment delivered as intended? All four weekly feedback reports required to be disseminated to each of the two treatment sites were delivered as planned (see Table 1), so the experimental treatment was delivered as intended. All feedback reports took the same format each week (see de Brito 2016; Appendix 3). There were no changes in the sergeants or inspectors at the treatment sites for the duration of the experiment, so reports were sent to the same individuals each time.

Figure shows the percentage of returns submitted for each site, for each week of the experiment. London Euston, one of the treatment sites, had the poorest return compliance of the four locations; however, this improved each week which could be correlated to delivery of the treatment feedback reports, as missing returns were highlighted in the weekly feedback reports. Control station Victoria followed a similar albeit less pronounced trend to that observed at London Euston. Control station London Bridge achieved $100 \%$ compliance throughout the duration of the experiment, slightly ahead of consistently high card return compliance by treatment station Waterloo (Fig. 3).

The number of patrol cards actually tasked to patrollers by supervisors on a day to day basis varied widely. As the experiment did not seek to influence the daily business as usual tasking of patrol cards to PCs and PCSOs by supervisors, the number of patrol cards assigned each day was based on the number of PCs and PCSOs available for patrol on each particular shift. That, in turn, depended on such variables such as annual leave, training commitments or court appearances.

Figure 4 shows the number of individual patrol cards assigned to officers for each site, for each week of the experiment. Both treatment and control sites assigned 


\begin{tabular}{|c|c|c|c|c|}
\hline \multicolumn{5}{|l|}{$100 \%$} \\
\hline \multicolumn{5}{|l|}{$95 \%$} \\
\hline $90 \%$ & & & 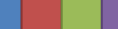 & \\
\hline $85 \%$ & & & & \\
\hline $80 \%$ & & & & \\
\hline $75 \%$ & & & & \\
\hline $70 \%$ & & & & \\
\hline \multicolumn{5}{|l|}{$65 \%$} \\
\hline $60 \%$ & Before & Week 1 & Week 2 & Week 3 \\
\hline$\square$ Euston (T) & $72.15 \%$ & $97.22 \%$ & $95.00 \%$ & $100.00 \%$ \\
\hline$\square$ Waterloo (T) & $100.00 \%$ & $96.43 \%$ & $100.00 \%$ & $100.00 \%$ \\
\hline$\square$ London Bridge (C) & $100.00 \%$ & $100.00 \%$ & $100.00 \%$ & $100.00 \%$ \\
\hline$\square$ Victoria (C) & $92.00 \%$ & $100.00 \%$ & $100.00 \%$ & $100.00 \%$ \\
\hline
\end{tabular}

Fig. 3 Weekly percentage of patrol cards returned

substantially fewer patrols as the weeks went by, and some sites virtually stopped hot spot patrols in week 3. London Euston, for example, deployed 79 patrols in the before week, compared to just 13 in the entire week 3, a percentage reduction in assigned patrols of $-83.5 \%$. This drop could have been due to the launch of a change in London Underground hours to run the trains all night (called 'Night Tube') on 19 August 2016. This major change in London transport fell during the second treatment week and meant that a large number of patrol officers across all London locations were diverted to focus their attention on the Underground for this event. This change is observed in both treatment and control groups, indicating that the treatment was not responsible for the change.

Analysis from this point onwards is therefore carried out in terms of percentage of visits carried out (completed versus required, as recorded on each individual patrol card), rather than based on the actual number of patrol visits. Using proportions of assigned patrols as the key indicator controls for the turbulent summer environment, controlling for the level of assignments as a key cause of raw numbers of hot spot

\begin{tabular}{|c|c|c|c|c|}
\hline \multicolumn{5}{|l|}{90} \\
\hline \multicolumn{5}{|l|}{80} \\
\hline \multicolumn{5}{|l|}{70} \\
\hline \multicolumn{5}{|l|}{60} \\
\hline \multicolumn{5}{|l|}{50} \\
\hline \multicolumn{5}{|l|}{40} \\
\hline \multicolumn{5}{|l|}{30} \\
\hline \multicolumn{5}{|l|}{20} \\
\hline \multicolumn{5}{|l|}{10} \\
\hline 0 & Before & Week 1 & Week 2 & Week 3 \\
\hline$\square$ Euston ( $\mathrm{T}$ ) & 79 & 36 & 20 & 13 \\
\hline Waterloo (T) & 41 & 28 & 16 & 21 \\
\hline$\square$ London Bridge (C) & 56 & 28 & 18 & 12 \\
\hline$\square$ Victoria (C) & 25 & 12 & 9 & 14 \\
\hline
\end{tabular}

Fig. 4 Weekly number of patrol cards assigned 
patrols. This procedure allows fair comparisons between sites with different numbers of required patrol visits.

\section{Patrol Dosage: Treatment Versus Treatment Versus Control}

Was a change in patrol dosage observed at either of the treatment stations during the experiment relative to control?

The answer to this question is yes, but in only one of the two tests. Both test sites were compared separately against the combined results of the two control sites (Fig. 5). When the two treatment sites, London Euston and London Waterloo, were analysed separately, the results were completely different. While the percentage of assigned patrols completed for each week of the experiment showed no substantial improvement in London Euston, the other treatment station, London Waterloo, saw a dramatic increase in visits achieved. For London Waterloo, percentage compliance in the 'before' week was at $28.2 \%$, which increased to $40.5 \%$ in week $1,62.1 \%$ in week 2 , concluding the experiment at $53.1 \%$ in week 3 , a percentage dosage still nearly double that which was observed in the before week. Figure 5 shows the relative percentage increase in compliance for each week for each location separately, using the percentage compliance in each site in the 'before week' as the zero-standard baseline for percentage change.

\section{Treatment Variations in Euston and Waterloo Stations}

While these two tests were not designed to be case studies, the results call for a presentation of qualitative data that may correlate with the different outcomes of the two treatment sites. At London Waterloo, patrol dosage increased by $22 \%$, while at Euston, it declined by $6 \%$. Yet the same planned treatment was deployed, at the same time on the same day. The stations are both similar in that they are both large hub stations and part of the same BTP division with the same chief superintendent was responsible for both locations, which had the same policing objectives, targets and

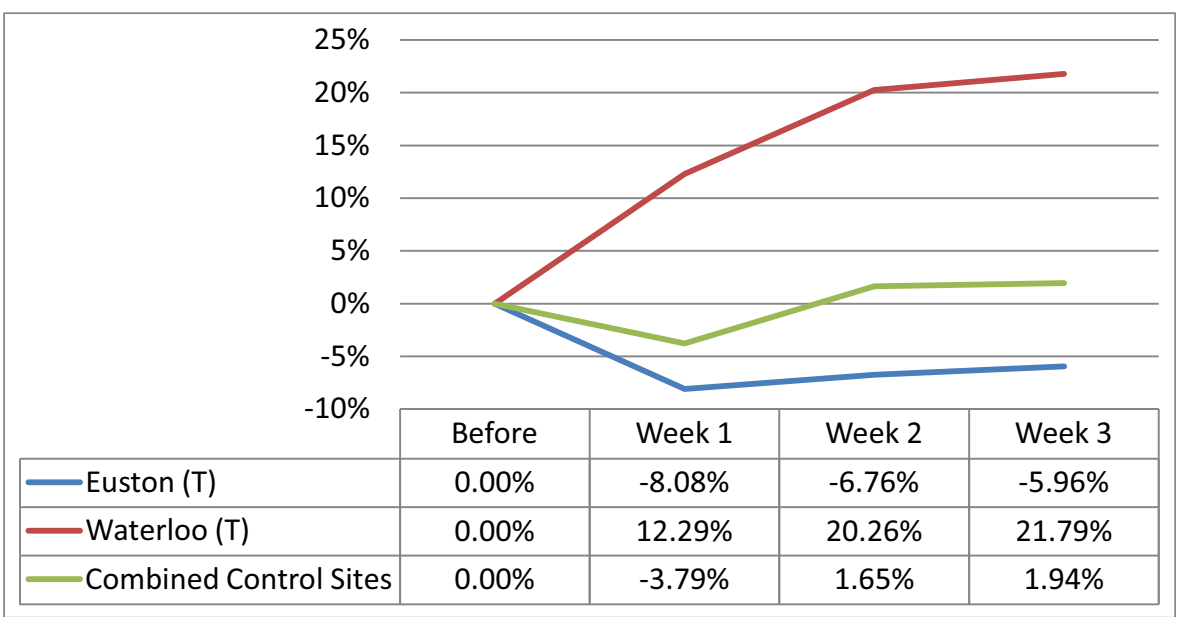

Fig. 5 Relative percentage change of proportion of patrol visits achieved at each treatment site and combined control sites (compared to before week as zero) 
challenges. The possible differences between the high-impact and no-impact results of tracking and feedback on patrol delivery include leadership style, turnover and other contextual factors. None of them can be said to be a clear explanation for the different results. But the mere fact of the difference suggests the importance of such factors in future research on tracking and feedback on proactive policing.

Varying Leadership Styles of Communication While the supervisors were asked to confirm receipt of the feedback report and confirm that the contents had been briefed out to those PCs and PCSOs patrolling, the experimental procedure did not specify how the feedback was to be briefed. Interviews with the sergeants at the experimental sites after completion of the experiment revealed that the method of briefing varied from person to person and place to place. Some simply forwarded on the report to their patrollers by email; some discussed it in the morning briefings. It is not clear which, if either, station used a more consistent method of communication. But based on qualitative sources, it appears that the more successful site was one that used more face-toface communication.

Turnover The difference in outcome is consistent with feedback working better where there is less turnover in leadership. London Waterloo, where feedback caused higher delivery of assigned patrols, had experienced strong and consistent leadership for several years with the same inspector responsible for the location for a prolonged period. This leader was well respected for his knowledge and experience. On the other hand, at London Euston, a temporary Inspector was appointed with responsibility for this station just 3 weeks prior to commencement of the experiment. This temporary inspector had not had time to become well respected, and as he was busy settling in, delivering preventative patrol may not have been a priority for him. What is clear is that the Inspector at London Waterloo was proactive and used the contents of the feedback reports to improve on his location's performance, through face-to-face meetings. The inspector at London Euston did not.

Based on these limited observations, it appears that 'hands on' people management was a key difference in feedback increasing patrol dosage. It was not sufficient to simply email out negative feedback and expect it to be acted upon by the recipients. Face-to-face meetings allowed an opportunity to both praise improvement and then raise goals even higher.

\section{Conclusion}

The two limited experiments reported here appeared to have been delivered as planned, but without a major implementation process in either site. In both sites, feedback was delivered. Yet in one site, feedback landed in the context of a stable leadership environment. In others, feedback landed in the midst of many other changes. It may not have been impossible for tracking and feedback to work in both environments. Yet it seems clear that any rollout of tracking and feedback must be resilient enough to succeed in a range of local leadership contexts.

The substantive conclusion of these two tests is therefore conditional. Tracking and feedback on hot spot patrol compliance worked, without a detailed implementation 
strategy, where there was stable leadership. It failed to have an impact where leadership was not stable.

The more important conclusions for tracking and feedback may be methodological (Drover and Ariel, 2015). Given the absence of automated data collection, there were not only substantial costs, but unanswerable questions about data integrity. Because the patrol cards themselves were not audited by the authors or anyone else, the meaning of the data cannot be entirely certain. That is always the case with self-reported performance data. Yet in that case, we can at least be assured that when a similar method was used by Sherman and Weisburd (1995) and compared to independent observer data, the results were highly correlated.

The more important limitation of the patrol card methods used in these tests is that the cost was unsustainable. Just the manual logging of visits by the BTP patrol administrator alone would have been a considerable investment in terms of employee time spent. Each patrol card would have taken approximately $1 \mathrm{~min}$ to log, with 428 being logged throughout the duration of the experiment. This equates to just over $7 \mathrm{~h}$ of time, which - considering this is for only four stations over a month long period - if extrapolated to the whole of BTP's patrolling workforce on a permanent basis, could be a full time job for two individuals (see also Ariel and Sherman 2012). Moreover, there is the risk of high rates of human error; an officer may forget to log their hot spot visit or fill in the patrol card retrospectively, forget to record visits or embellish the number of visits carried out. The administrator may type the number of visits incorrectly and the paper patrol cards may be lost completely. The list of threats to data accuracy could go on.

It is clear that if any agency wishes to use hot spot patrol as their main patrol method, an automatic hot spot patrol monitoring system must be prioritised for investment. Due to the unique environments where BTP hot spots are located, different from all other UK police forces, they cannot rely on Airwave GPS to provide accurate tracking data, so investment in new technology is required. While the hypothesis that patrol feedback can increase patrol dosage has only been supported by one of this article's two tests, it remains a promising theory. Based on previous literature (e.g. Sherman et al. 2014b) combined with these results, feedback remains the most promising avenue for increasing hot spot patrols, which in turn remain a promising avenue for reducing crime and disorder. More experiments are required which analyse data captured by an automated system, for a longer time period, and with more varied treatment conditions, in order to determine the best approach to track and feedback what policing is delivered.

Acknowledgements This study was made possible by a College of Policing matched bursary with the British Transport Police to support first author's studies in the Cambridge University Master's degree course in applied criminology and police management. The first author is indebted to her colleagues Mohammed Zaman, Mark Newton and Steff Sharp for their invaluable assistance with the research.

Author Contributions Charlotte de Brito BSc (Hons) MSt (Cantab) is Head of Crime Reduction in the British Transport Police Force Headquarters based in London.

Barak Ariel $\mathrm{PhD}$ (Hebrew $\mathrm{U}$ ) is Lecturer in Experimental Criminology at the University of Cambridge and Senior Lecturer in Criminology at the Hebrew University of Jerusalem.

Open Access This article is distributed under the terms of the Creative Commons Attribution 4.0 International License (http://creativecommons.org/licenses/by/4.0/), which permits unrestricted use, distribution, and reproduction in any medium, provided you give appropriate credit to the original author(s) and the source, provide a link to the Creative Commons license, and indicate if changes were made. 


\section{References}

Ariel, B. (2012). Deterrence and moral persuasion effects on corporate tax compliance: findings from a randomized controlled trial. Criminology, 50(1), 27-69.

Ariel, B., \& Partridge, H. (2016). Predictable policing: measuring the crime control benefits of hotspots policing at bus stops. Journal of Quantitative Criminology. 1-25. https://doi.org/10.1007/s10940-0169312-y

Ariel, B., \& Sherman, L. (2012). Operation "BECK" Results from the First Randomised Controlled Trial on Hotspot Policing in England and Wales [PowerPoint], Presentation to Cambridge 2012 Conference on Evidence Based Policing, available online http://www.crim.cam.ac.uk/events/conferences/ebp/2012/. Accessed 2 May 2016.

Ariel, B., \& Smallwood, J. (2014). The Birmingham Hot Spots Experiment: Operation Savvy [PowerPoint], Presentation to Cambridge 2014 Conference on Evidence Based Policing, available online http://www. crim.cam.ac.uk/events/conferences/ebp/2014/. Accessed 18 July 2016.

Ariel, B., Weinborn, C., Sherman, L.W. (2016). "Soft" policing at hot spots - do police community support officers work? A randomized controlled trial. Journal of Experimental Criminology, 12(3), 277-317.

Braga, A., Papachristos, A., \& Hureau, D. (2012). Hot spots policing effects on crime. Campbell Systematic Reviews, 2012, 8.

De Brito, C. (2016). Will providing tracking feedback on hot spot patrols affect the amount of patrol dosage delivered? A level 4 experiment. Thesis submitted for the MSt in applied criminology and police management, University of Cambridge, Institute of Criminology.

Drover, P., \& Ariel, B. (2015). Leading an experiment in police body-worn video cameras. International Criminal Justice Review, 25, 80-97. https://doi.org/10.1177/1057567715574374.

Gibson, C. M., Slothower, M., \& Sherman, L. (2017). Sweet spots for hot spots? A cost-effectiveness comparison of two patrol strategies. Cambridge Journal of Evidence-Based Policing, 1, 4.

Goddard, N., \& Ariel, B (2014). 'How much time should officers spend in night-time economy hot spots? Lessons from a "Randomized Controlled Trial in Northern Ireland". Presented at the Annual American Society of Criminology (San Francisco, CA, 18-20 November 2014)

Koper, C. S. (1995). Just enough police presence: reducing crime and disorderly behaviour by optimizing patrol time in crime hot spots. Justice Quarterly, 12, 649-672.

Kumar, S. (2015). Tracking hot spot patrol and violent crime in Trinidad and Tobago: a quasi-experimental analysis. Cambridge, England: Cambridge Centre for Evidence-Based Policing Ltd (www.cambridgeebp.net). Cited by Sherman, L. W. and Strang, H. (2015). Evidence-based policing in 100 milestones: a video course in 26 chapters. Cambridge Centre for Evidence-Based Policing. Available from http://sebp. police.uk. Accessed 23 April 2016.

Sherman, L. W. (1993). Defiance, deterrence and irrelevance: a theory of the criminal sanction. Journal of Research in Crime and Delinquency, 30, 445-473.

Sherman, L. W. (1995). Hot spots of crime and criminal careers of places. In D. Weisburd \& J. Eck (Eds.), Crime and place. Crime prevention studies (Vol. 1, pp. 35-52). Monsey: Criminal Justice Press.

Sherman, L. W. (1997). Chapter two in Sherman, L.W., Gottfredson, D., MacKenzie, D., Eck, J., Reuter, P. and Bushway, S. Preventing crime: what works, what doesn't, what's promising? Washington: US Department of Justice.

Sherman, L. W. (2007). The power few hypothesis: experimental criminology and the reduction of harm. Journal of Experimental Criminology, 3, 299-321.

Sherman, L. W. (2013). The rise of evidence-based policing: targeting, testing and tracking. In M. Tonry (Ed.), Crime and justice in America, 1975-2025, Crime and justice (Vol. 42, pp. 377-452). Chicago: University of Chicago Press.

Sherman, L.W., \& Strang, H. (2015). Evidence-based policing in 100 milestones: a video course in 26 chapters. Cambridge Centre for Evidence-Based Policing. Available from http://sebp.police.uk. Accessed 23 April 2016.

Sherman, L. W., \& Weisburd, D. (1995). General deterrents of police patrol in crime hotspots: a randomized controlled trial. Justice Quarterly, 12, 625-648.

Sherman, L. W., Gartin, P. R., \& Buerger, M. E. (1989). Hot spots of predatory crime: routine activities and the criminology of place. Criminology, 27(1), 27-56.

Sherman, L. W., Williams, S., Ariel, B., Strang, L. R., Wain, N., Slothower, M., \& Norton, A. (2014b). An integrated theory of hot spots patrol strategy implementing prevention by scaling up and feeding back. Journal of Contemporary Criminal Justice, 30, 95-122. 
Telep, C. W., Mitchell, R. J., \& Weisburd, D. (2012). How much time should the police spend at crime hot spots? Answers from a police agency directed randomized field trial in Sacramento, California. Justice Quarterly, 1-29.

Telep, C. W., Mitchell, R. J., \& Weisburd, D. (2014). How much time should the police spend at crime hot spots? Answers from a police agency directed randomized field trial in Sacramento, California. Justice Quarterly, 31(5), 905-933.

Wain, N., \& Ariel, B. (2014). The tracking of police patrol. Policing: A Journal of Policy and Practice, 8(3), 274-283.

Weisburd, D. (2015). The law of crime concentration and the criminology of place. Criminology, 53, $133-157$.

Weisburd, D., Groff, E., Jones, G., Amendola, K. L., \& Cave, B. (2012a). The Dallas AVL Experiment: evaluating the use of automated vehicle locator technologies in policing. Washington: Police Foundation.

Weisburd, D. L., Groff, E. R., \& Yang, S. -M. (2012b). The criminology of place: street segments and our understanding of the crime problem. New York: Oxford University Press.

Williams, S., \& Coupe, R. T. (2017). Frequency vs. length of hot spots patrols: a randomised controlled trial. Cambridge Journal of Evidence-Based Policing, 1, 1. 